\title{
Erratum to: investigation of metabolites for estimating blood deposition time
}

\author{
Karolina Lech ${ }^{1}$ - Fan Liu ${ }^{1,2,3}$ • Sarah K. Davies ${ }^{4}$ Katrin Ackermann ${ }^{5}$. Joo Ern Ang ${ }^{6}$. \\ Benita Middleton $^{4}$ • Victoria L. Revell ${ }^{4}$. Florence I. Raynaud ${ }^{6}$. Igor Hoveijn ${ }^{7}$. \\ Roelof A. Hut ${ }^{7}$ - Debra J. Skene ${ }^{4}$. Manfred Kayser ${ }^{1}$
}

Published online: 24 August 2017

(C) Springer-Verlag GmbH Germany 2017

Erratum to: Int J Legal Med (2017)

https://doi.org/10.1007/s00414-017-1638-y

The original version of this article unfortunately contained an error in author name. The name has been corrected above as Florence I. Raynaud, respectively.

The online version of the original article can be found at https://dx.doi. org/10.1007/s00414-017-1638-y

Manfred Kayser

m.kayser@erasmusmc.nl

1 Department of Genetic Identification, Medical Center Rotterdam,

Erasmus MC University, Rotterdam, The Netherlands

2 Key Laboratory of Genomic and Precision Medicine, Beijing Institute of Genomics, Chinese Academy of Sciences, Beijing, China

3 University of Chinese Academy of Sciences, Beijing, China

4 Chronobiology, Faculty of Health and Medical Sciences, University of Surrey, Guildford, UK

5 EaStCHEM School of Chemistry, Biomedical Sciences Research Complex and Centre of Magnetic Resonance, University of St. Andrews, St. Andrews, UK

6 Cancer Research UK Cancer Therapeutics Unit, Division of Cancer Therapeutics, The Institute of Cancer Research, London, UK

7 Groningen Institute for Evolutionary Life Sciences, Chronobiology Unit, University of Groningen, Groningen, The Netherlands 